\title{
DETECTION OF LYING TREE STEMS FROM AIRBORNE LASER SCANNING DATA USING A LINE TEMPLATE MATCHING ALGORITHM
}

\author{
Eva Lindberg ${ }^{\mathrm{a}, \mathrm{b}}$ *, Markus Hollaus ${ }^{\mathrm{a}}$, Werner Mücke ${ }^{\mathrm{a}}$, Johan E. S. Fransson ${ }^{\mathrm{b}}$, Norbert Pfeifer ${ }^{\mathrm{a}}$ \\ ${ }^{a}$ Department of Geodesy and Geoinformation, Vienna University of Technology, Austria \\ ${ }^{\mathrm{b}}$ Department of Forest Resource Management, Swedish University of Agricultural Sciences, Umeå, Sweden
}

Commission III, WG III/2

KEY WORDS: 3D modelling, Point cloud processing, Line detection, ALS data

\begin{abstract}
:
Dead wood is an important habitat characteristic in forests. However, dead wood lying on the ground below a canopy is difficult to detect from remotely sensed data. Data from airborne laser scanning include measurement of surfaces below the canopy, thus offering the potential to model objects on the ground. This paper describes a new line template matching algorithm for detecting lines along the ground. The line template matching is done directly to the laser point cloud and results in a raster showing the support of the line in each raster cell. Line elements are vectorized based on the raster to represent lying tree stems. The results have been validated versus field-measured lying tree stems. The number of detected lines was 845, of which 268 could be automatically linked to the 651 field-measured stems. The line template matching produced a raster which visually showed linear elements in areas where lying tree stems where present, but the result is difficult to compare with the field measurements due to positioning errors. The study area contained big piles of storm-felled trees in some places, which made it an unusually complex test site. Longer line structures such as ditches and roads also resulted in detected lines and further analysis is needed to avoid this, for example by specifically detecting longer lines and removing them.
\end{abstract}

\section{INTRODUCTION}

Habitat management requires data on habitat characteristics. This is currently based on field visits combined with satellite imagery or aerial images (Vierling et al., 2008). In forest areas, dead wood lying on the ground is an important habitat characteristic. However, the conditions below a canopy are usually impossible to determine from passive remote sensing imagery.

Data from airborne laser scanning (ALS) are 3D measurements of light reflections from the ground and other items. Since part of the laser light can pass through gaps in the canopy, the ALS data include measurements of surfaces below the topmost canopy layer. This makes it possible to derive a digital terrain model (DTM) even in dense forests (Sithole and Vosselman, 2003) and also offers the potential to describe objects close to the ground, for example, linear elements such as hedgerows and ditches (Bailly et al., 2008).

ALS data have been related to animal habitat data, this far mostly for birds (e.g., Hill et al., 2004; Hinsley et al., 2008; Lesak et al., 2011), but also for forest-dwelling beetles (Müller and Brandl, 2009). The amount of lying dead wood (Pesonen et al., 2008) and standing dead wood (Bater et al., 2009) in forests has been estimated from ALS data with area-based approaches (i.e., based on the correlation between the total amount of dead wood and measures derived from the ALS data in 900 to 1600 $\mathrm{m}^{2}$ raster cells).

The analyses above have not utilized the detailed 3D structure of ALS data, which may be done with, for example, object based image analysis (Blanchard et al., 2011). Rasterization and image processing has provided good results for detection of fallen trees in forested areas from ALS data (Mücke et al., 2013).

* Corresponding author, eva.lindberg@slu.se.
Line detection in binary images is often done with the Hough transform (Gonzalez and Woods, 2008). Using this method, the image is transformed into a parameter space by generating lines in all directions through all positive pixels. The line parameters correspond to local maxima in parameter space. The Hough transform can also be applied in a moving window to detect local lines. For line detection in point clouds, an alternative is the random sample consensus (RANSAC) algorithm (Fischler and Bolles, 1981). This algorithm randomly selects the minimum number of points to fit a line (i.e., two) from the dataset and the line is generated. The points within a maximum distance from the line are defined as the consensus set (i.e., inliers) and a new line is fitted to the consensus set. This is repeated for a number of iteration and the line with the best fit for the consensus set is selected.

This paper presents a new line template matching method to identify tree stems lying on the ground from ALS data. The line template matching is applied directly to the laser point cloud to utilize the information without a rasterization step. The algorithm is also based on a voting scheme. The different lines are generated systematically. The final results are validated versus field-measured lying tree stems. 


\section{MATERIALS}

\subsection{Study area}

The study area (Figure 1) is located in the southwest of Sweden (Lat. $58^{\circ} \mathrm{N}$, Long. $13^{\circ} \mathrm{E}$ ). Most of the area is covered with managed hemi-boreal forest. The most common tree species are Norway spruce (Picea abies), Scots pine (Pinus sylvestris), and birch (Betula spp.). On January 14, 2007, the area was struck by the storm Hanno (Schmidt, 2007), in Sweden also known as Per, resulting in a large amount of storm-felled trees.

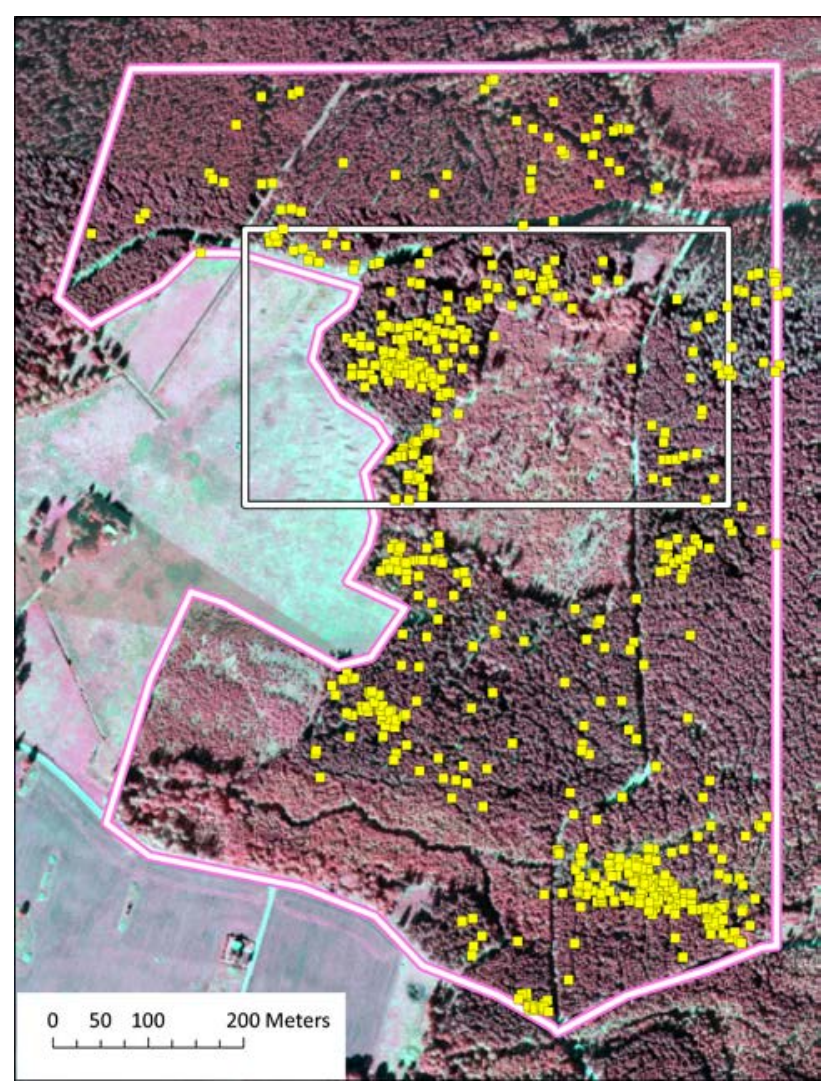

Figure 1. Study area with field-measured lying tree stems (yellow dots) on a false colour composite aerial image. The pink boundary marks the inventory area. The white box contains a big pile of storm-felled trees (left-middle), low vegetation with few or no storm-felled trees (middle) and single storm-felled trees (right). To the right of the low vegetation is a road in north-south direction. To the left of the pink boundary is an agricultural field outside of the inventory area where stems have been intentionally placed but not included in the field data.

\subsection{Field data}

An area, 54 ha in size, with remaining storm-felled trees was selected for inventory. During April 2007, all horizontal and leaning tree stems were measured within the selected area. For each tree stem, a number of attributes were recorded: direction in the horizontal plane, tree species, length, and diameter. For horizontal tree stems the height above the ground was recorded at $1.3 \mathrm{~m}$ from the root end, and for leaning tree stems the slope versus the vertical direction was recorded. The position of each tree stem was measured using a GPS placed at the root end. The positioning error was approximately $5 \mathrm{~m}$. The number of horizontal tree stems was 651 and the number of leaning stems was 105.

\subsection{ALS data}

The ALS data were collected on April 24, 2007, with a TopEye system S/N 425 carried by a helicopter at $130 \mathrm{~m}$ above the ground. The first and last returns were recorded and the average return density was $69 \mathrm{~m}^{-2}$. The accuracy of the ALS data was $<0.1 \mathrm{~m}$ in vertical direction and $<0.3 \mathrm{~m}$ in horizontal direction (communication with the surveying company Blom).

\section{METHODS}

\subsection{DTM creation}

The DTM was computed with the robust filtering method proposed by Kraus and Pfeifer (1998). It is a so-called "surfacebased" filter, based on linear prediction with individual accuracies for each ALS echo (Shan and Toth, 2009). In the SCOP++ software (TU Vienna, 2013), which was used for the calculations, the robust filtering is implemented following the hierarchic approach as presented by Pfeifer et al. (2001). In this case the method works stepwise in a "coarse-to-fine" strategy. This means that it starts with a set of ALS echoes thinned-out within a regular grid and using the second lowest point inside the grid cell for the computation of a coarse initial DTM with robust filtering. Only echoes close to this initial surface are kept for further consideration. For the next step a denser set of echoes is used (i.e., less thinned-out) and the filtering starts again, producing a finer DTM. In the applied settings, three iterations were performed till the final DTM was obtained with a grid size of $1.0 \mathrm{~m}$. The method has proven to perform well in forested areas with high amounts of near-ground vegetation (e.g., Sithole and Vosselman, 2003).

\subsection{Line template matching}

The basic assumption for detecting lying stems in the ALS data was that they could be found by matching a line template to near terrain ALS returns. Therefore, in a first step, possible lying stem positions in the $\mathrm{x}-\mathrm{y}$ domain were detected and in a second step the height homogeneity along the stems as well as in the neighbourhood were evaluated, which are both important measures for the final stem identification. Finally, the detected lying stems were vectorized to be validated with field data. All analysis was based on raster cells with a size of $0.5 \times 0.5 \mathrm{~m}^{2}$. The parameters of the method were selected to define line elements corresponding to tree stems typically found in the area. To apply the template matching algorithm to the ALS data, the normalized height (i.e., the height above the DTM) was calculated for each return. Since the lying stems commonly had heights of maximum $1.0 \mathrm{~m}$ above the terrain, the line template matching algorithm was applied to all returns with normalized heights $\geq 0.2 \mathrm{~m}$ and $\leq 1.0 \mathrm{~m}$. The limit of $0.2 \mathrm{~m}$ was used to exclude terrain points due to the uncertainty of defining the forest terrain. For each raster cell, the mean normalized height $h_{\text {mean }}$ was calculated of all returns within $0.25 \mathrm{~m}$ from the raster cell centre (i.e., in the circle inscribed in the raster cell; Figures $2 \mathrm{a}$ and $3 \mathrm{a}$ ). Returns within a vertical distance of $\pm 0.25 \mathrm{~m}$ from $h_{\text {mean }}$ were selected for the line template matching. The number of returns was counted within a line template with the size 0.5 $\times 10 \mathrm{~m}^{2}$ centered on the raster cell. The line template was rotated in steps of $2^{\circ}$ and the angle $\alpha_{\max }$ was selected for which the number of returns within the line template was maximized (Figures 2b and $3 \mathrm{~b}$ ).

To analyse the height homogeneity along the potential stem, the line template was divided into intervals of $0.2 \mathrm{~m}$ length for $\alpha_{\max }$ in each raster cell. For each interval, the mean normalized 
height of all returns within the interval was calculated (Figures 2c and 3c). The number of intervals for which the difference between the mean height and $h_{\text {mean }}$ was less than $\pm 0.25 \mathrm{~m}$ was stored and denoted $n_{\text {line, } 1}$. To analyse the neighbouring height homogeneity, an additional grid with a cell size of $0.2 \mathrm{~m}$ was defined within a circle of $5 \mathrm{~m}$ radius around each raster cell centre (Figures $2 \mathrm{~d}$ and $3 \mathrm{~d}$ ). The number of grid cells where the difference between the mean height of all returns and $h_{\text {mean }}$ was less than $\pm 0.25 \mathrm{~m}$ and with distance less than $\pm 0.5 \mathrm{~m}$ from the template midline (i.e., inside the shaded grid cells in Figures $2 \mathrm{~d}$ and 3d) was stored and denoted $n_{\text {line,2. }}$. The number of such grid cells with distance more than $\pm 0.5 \mathrm{~m}$ from the template midline (i.e., outside of the shaded grid cells in Figures $2 \mathrm{~d}$ and 3d) was stored and denoted $n_{\text {circle }}$. A ratio $r_{\text {supp }}$ was derived as $n_{\text {line }, 1} \times$ $n_{\text {line }, 2} / n_{\text {circle }}$ to measure the support of the line in each raster cell.
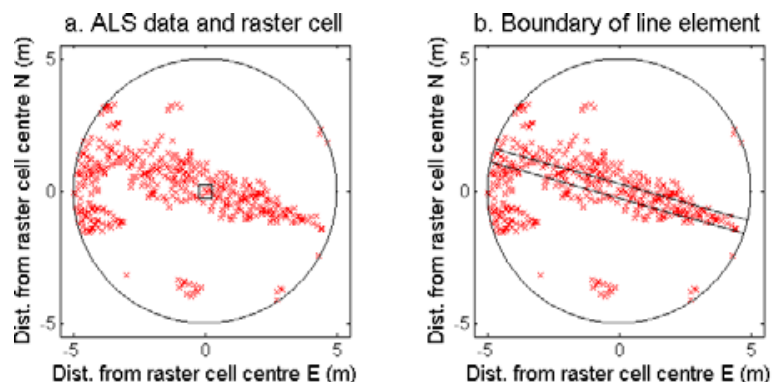

Dist. from raster cell centre $E(m)$

c. Intervals of line element

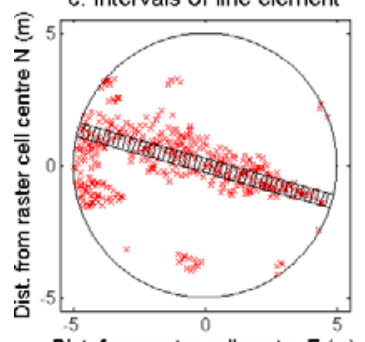

Dist. from raster cell centre $\mathbf{E}(\mathrm{m})$

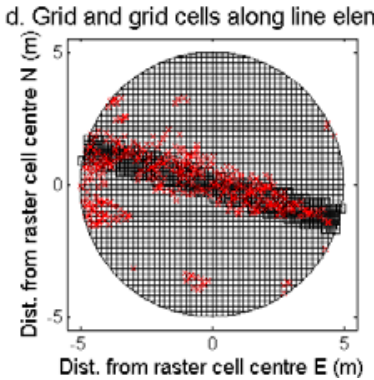

Figure 2. Example of line template matching in case of a lying tree stem measured in field. ALS data between $\geq 0.2 \mathrm{~m}$ and $\leq 1.0 \mathrm{~m}$ above the DTM are shown in red.
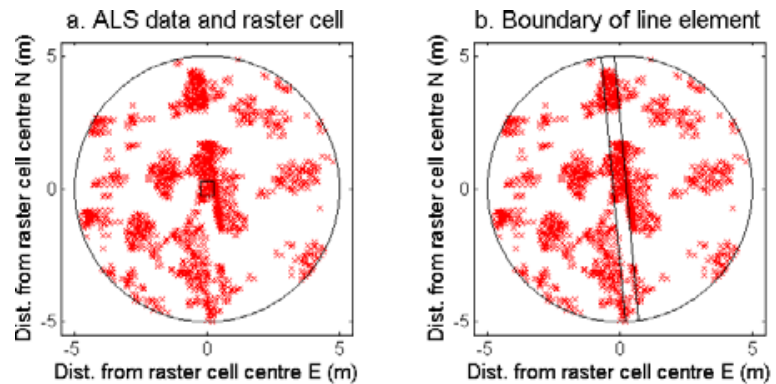

c. Intervals of line element

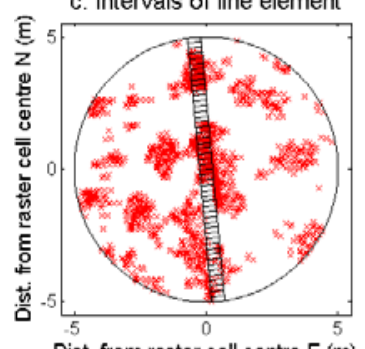

Dist. from raster cell centre $\mathbf{E}(\mathrm{m})$

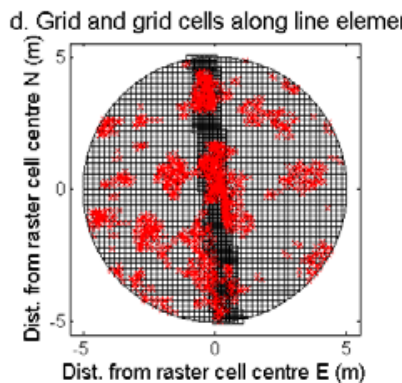

Figure 3. Example of line template matching in case of low vegetation and no lying tree stem measured in field. ALS data between $\geq 0.2 \mathrm{~m}$ and $\leq 1.0 \mathrm{~m}$ above the DTM are shown in red.
Finally, lines were vectorized from the raster of $r_{\text {supp }}$ in iterations. For each iteration, the raster cell of $r_{\text {supp }}$ with maximum value within the entire raster was identified. A line was defined corresponding to $\alpha_{\max }$ and raster cells with horizontal distance less than $d_{\max }$ from the raster cell centre and $0.5 \mathrm{~m}$ from the line were selected. If the fraction of such raster cells with $r_{\text {supp }}$ greater or equal to 10 was greater or equal to 0.5 , a line was vectorized with length $2 \times d_{\max }$ and angle $\alpha_{\max }$. The raster cells within the line were set to zero and the next iteration followed. The iteration stopped when the maximum value was less than 10 . The vectorization was done in two steps. In the first step, $d_{\max }$ was set to $25 \mathrm{~m}$ to detect long lines corresponding to ditches, roads and other similar structures. In the second step, raster cells at lines vectorized in the first step were excluded and $d_{\max }$ was set to $5 \mathrm{~m}$.

\subsection{Validation}

The detected lines $i$ were linked to the field-measured horizontal tree stems $j$ based on the horizontal distance $d_{i j}$ and the difference in direction in the horizontal plane $\Delta \alpha_{i j}$. The distance was measured in meters and the difference in direction was measured in radians. A line and a field-measured stem formed a pair only if $d_{i j}$ was less than $10 \mathrm{~m}, \Delta \alpha_{i j}$ was less than $\pi / 6$, and the midpoint of the line and stem was less than $10 \mathrm{~m}$ from the line defined through the stem and line, respectively. Only detected lines inside the inventory area were included. For each pair of line and field-measured stem, a weight $w_{i j}$ was calculated (1).

$$
w_{i j}=\frac{1}{d_{i j}^{2}+1}+\frac{1}{\Delta \alpha_{i j}^{2}+(\pi / 3)^{2}}
$$

The pairs were linked in order of decreasing $w_{i j}$ and only one field-measured stem or line was linked to each line or stem (i.e., one-to-one linking). The number of linked lines and fieldmeasured stems were counted and related to the total number of lines and field-measured stems, respectively.

\section{RESULTS AND DISCUSSION}

The analysis of the height homogeneity along the line templates (i.e., $\left.n_{\text {line, } 1}\right)$ resulted in high values where lying stems were present, but also in areas with dense low vegetation (Figure 4). Local differences in the return density at the border between overlap and no overlap between laser scanning strips also resulted in high values. The reason was that the line template matching selected the angle corresponding to a line along the border since other directions included the area with lower return density. The same was the case for the analysis of the neighbouring height homogeneity (i.e., $n_{\text {line, } 2}$ ). The ratio $r_{\text {supp }}$ provided high values where lying stems were present and lower values in areas with dense low vegetation. Additionally, the borders did not result in high values of $r_{\text {supp }}$. However, longer line structures such as ditches and roads also resulted in high values of $r_{\text {supp. }}$.

The analysis of the height homogeneity was a raster approach. An alternative raster approach would be to do line template matching on a raster of, for example, normalized heights (i.e., a normalized digital surface model; nDSM). However, rasterization would not utilize all information in the point cloud since each raster cell would be represented only by one value. The line template matching in this paper uses more information from the point cloud and the analysis of the height homogeneity is done on the line identified from the point cloud. 
The vectorization of the line elements detected lines in the areas with lying stems. However, even though longer lines had been vectorized and removed, short lines were still detected along the ditches and roads. In the area with low vegetation, single lines were detected. For some of them, manual inspection of the ALS data revealed that line structures were present. Such line

\section{a. Number of returns within the line template for $\boldsymbol{\alpha}_{\max }$}

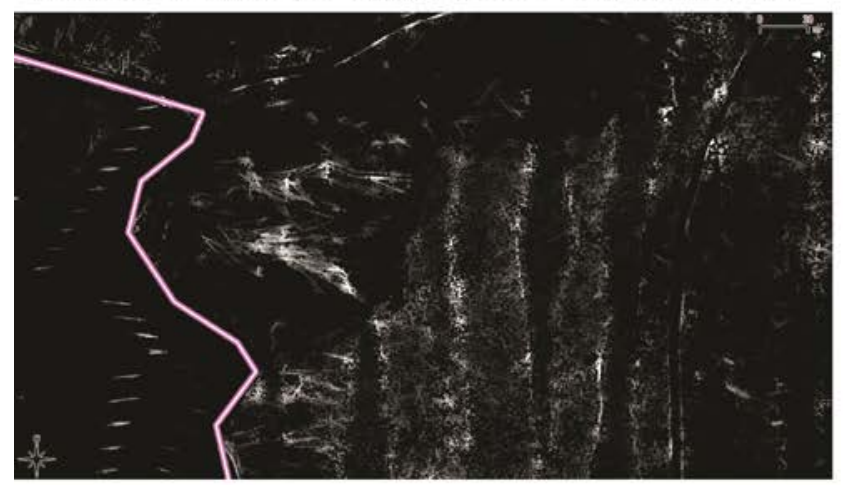

C. Number of grid cells $n_{\text {line, } 2}$

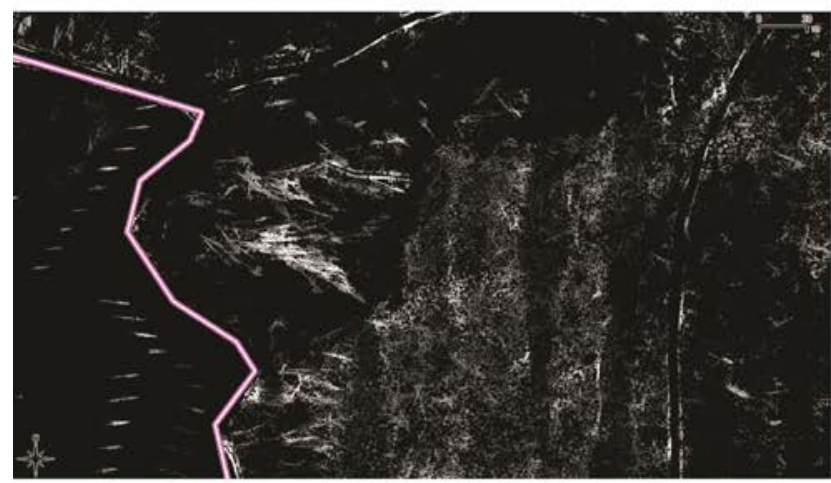

e. Vectorized lines with length $10 \mathrm{~m}$

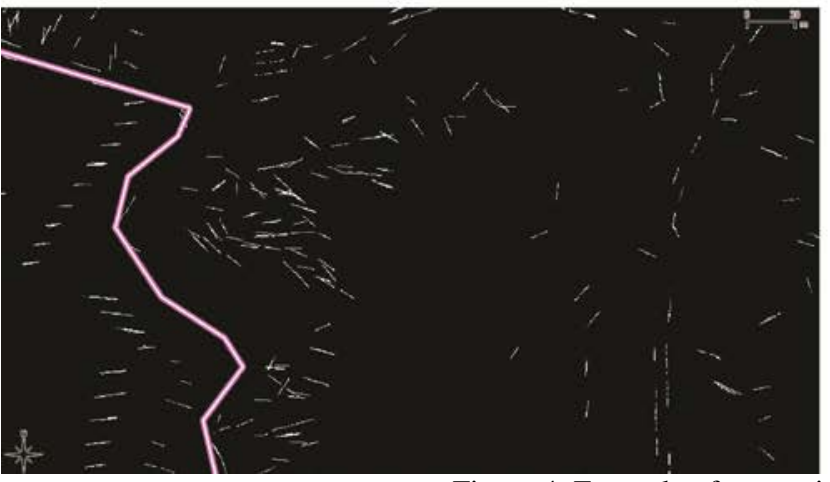

Figure 4. Example of rasters inside the white box in Figure 1.

The result from the linking (Figure 5) also showed that lines were detected along ditches and roads although no fieldmeasured stems were present and that not all stems were detected.

The line vectorization for the whole study area followed the same pattern as for the example: Lines were detected where lying stems were present, but also along ditches and roads (Figure 6). Since lines can be detected along the whole stretch of a ditch or a road, the amount of erroneously detected lines were big in some areas. The inventory area contained a large amount of storm-felled trees and the line template matching did structures might correspond to other objects than lying stems, for example stone walls, but in some cases the object was clearly a lying stem. This might be due to that lying stems in that area were not found during the field inventory.

\section{b. Number of intervals $n_{\text {line.1 }}$}

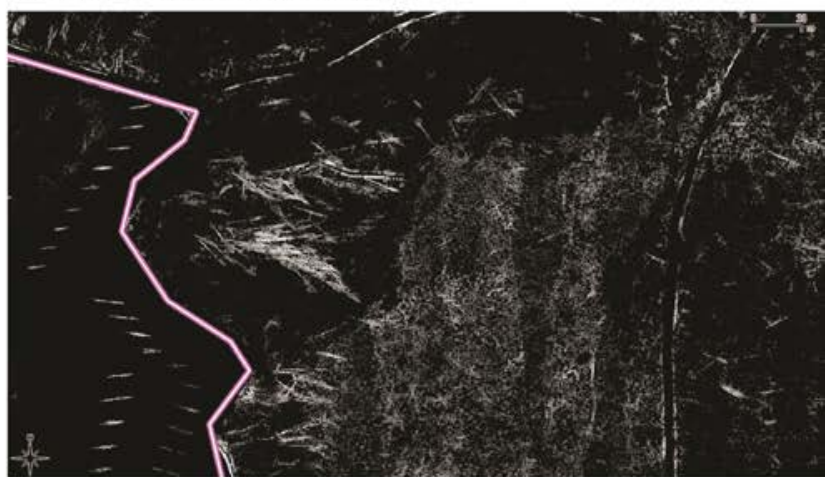

d. Support of the line $r_{\text {supp }}$

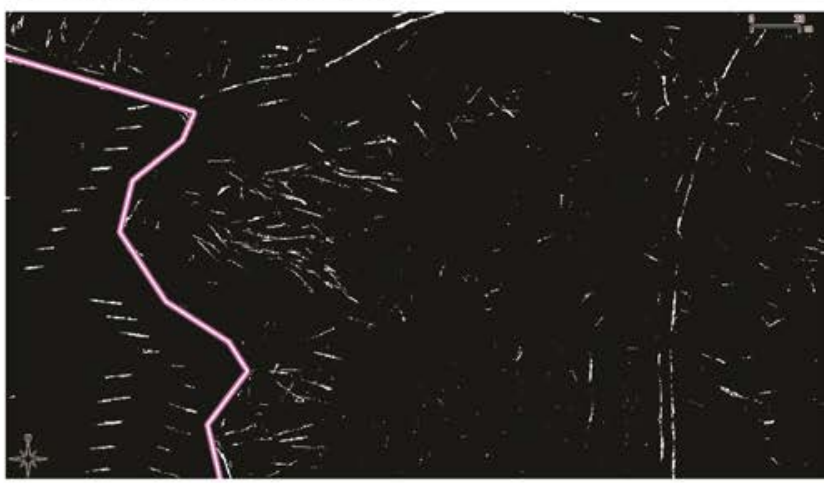

f. Vectorized lines and field-measured stems

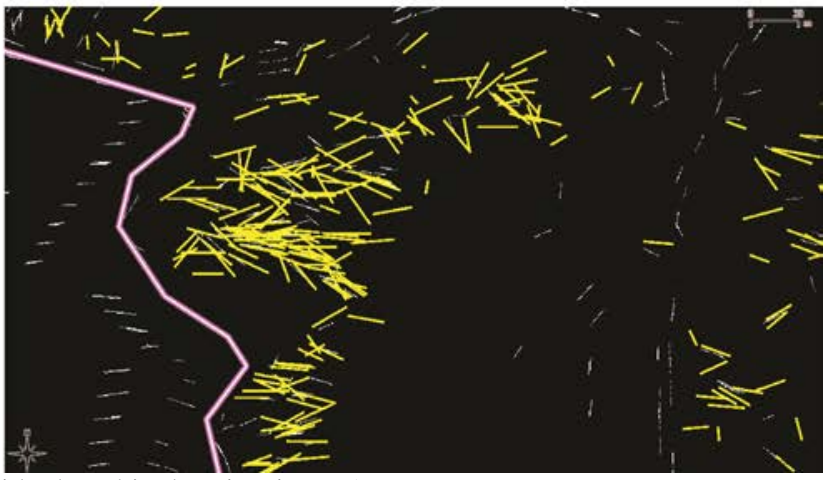

not give by hand all lying stems, especially for the piles of trees that were found in a few places.

The line template matching produced a raster which visually showed linear elements, but the vectorization failed to identify all lying stems. The total number of detected lines was 845 in the inventory area. The validation versus the field data showed that 268 field-measured stems and detected lines could be automatically linked. This corresponds to $41 \%$ of the fieldmeasured stems and $32 \%$ of the detected lines. The differences between the detected lines and the field-measured stems were due to detection errors mentioned above, but also positioning errors and in some cases incompleteness of the field data. 


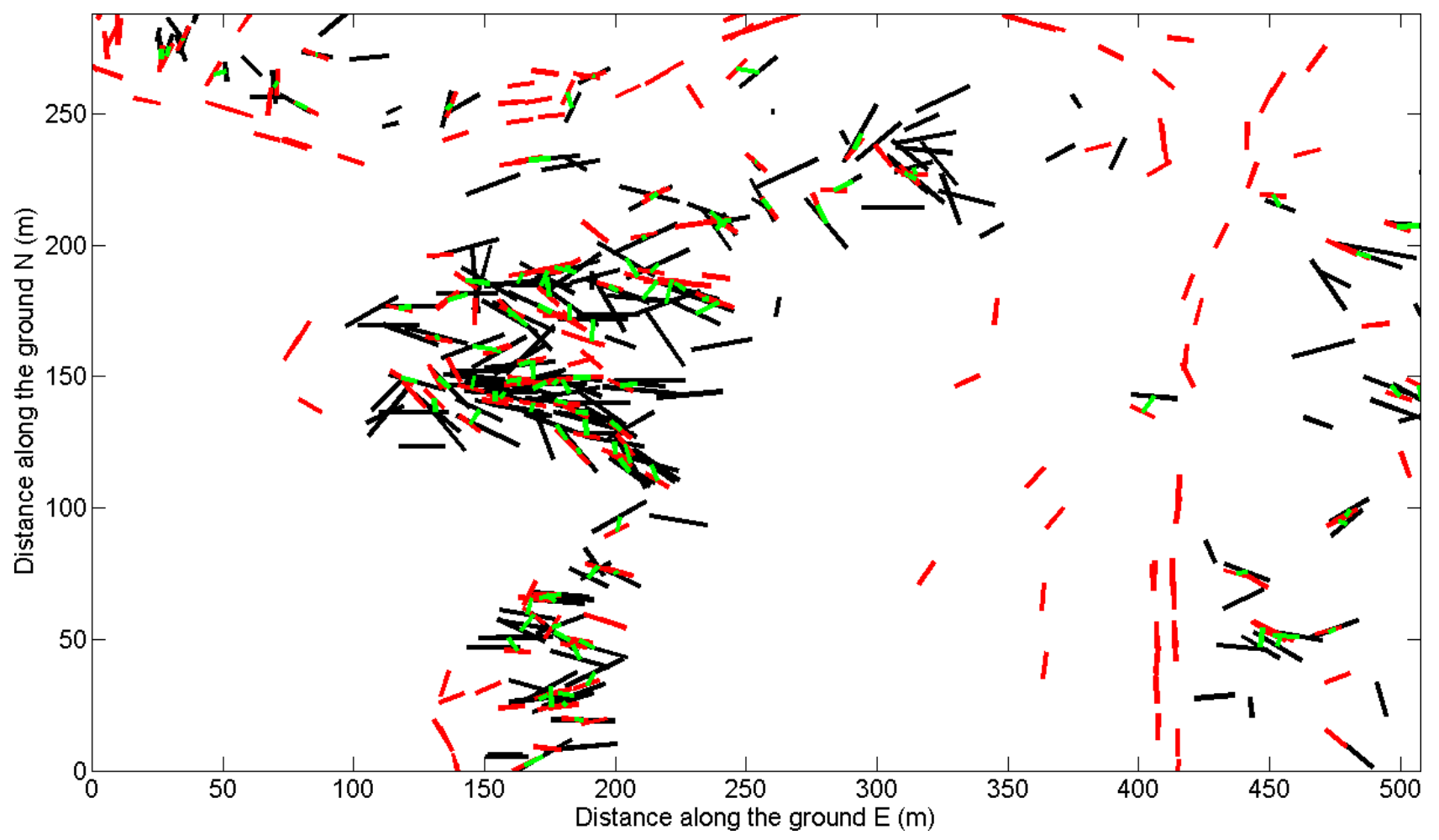

Figure 5. Field-measured stems (black), detected lines (red), and the links between them (green) inside the white box in Figure 1. Only stems and lines inside the inventory area are shown.

a. Detected lines (blue) and linked subset (yellow)

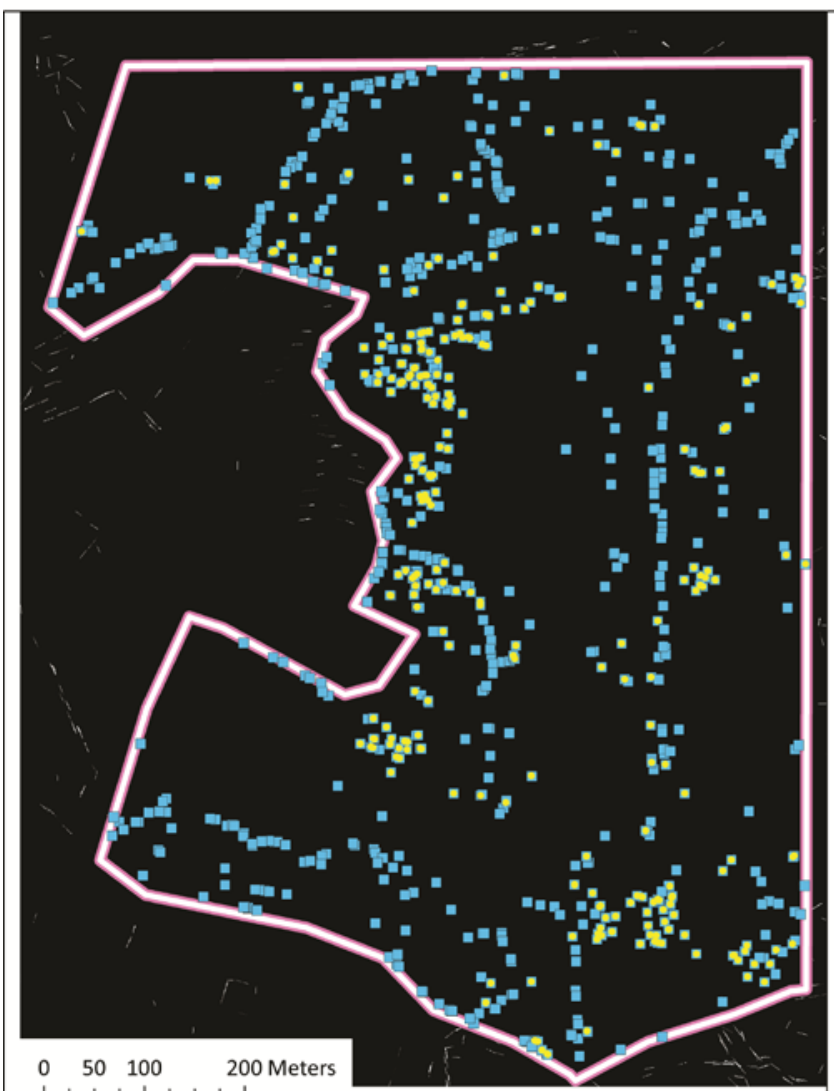

b. Field-meas. stems (yellow) and linked subset (blue)

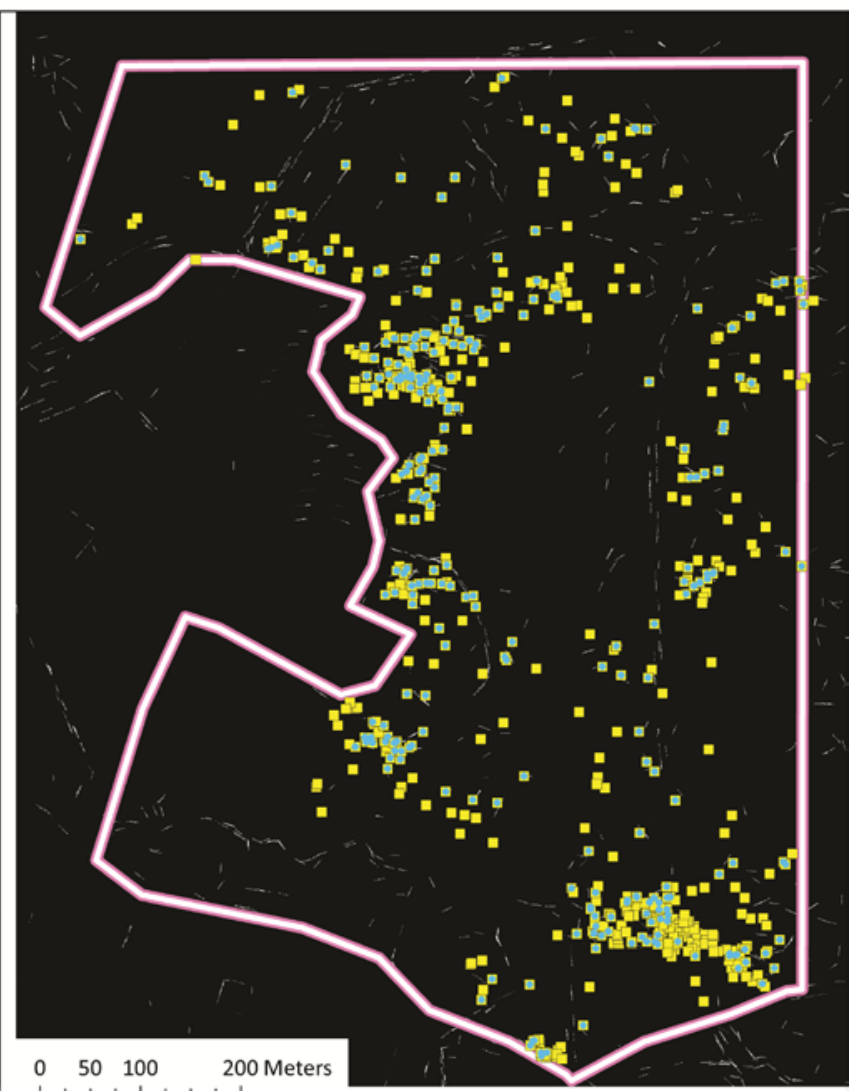

Figure 6. The linking between lines detected from the line template matching algorithm and the field-measured stems in the inventory area on a raster image of the vectorized lines. All detected lines shown in blue and the subset of lines linked to field-measured stems in yellow (a). All field-measured stems shown in blue and the subset of stems linked to detected lines in yellow (b). 


\section{CONCLUSIONS}

This paper has introduced a new algorithm to detect line structures along the ground in point clouds from airborne laser scanning with the purpose to identify lying tree stems. The algorithm consists of line template matching directly to the laser point cloud and vectorization of lines from the raster produced by the line template matching. The algorithm resulted in a raster which visually showed linear elements, but the results are difficult to validate with automatic analysis due to positioning errors and the complex site conditions.

This is the first demonstration of the method and there are several potential improvements. To improve the performance, the parameters could be tuned (i.e., the height limits, the size of the raster cells, and the size of the line element). Common reasons for not detecting stems were that they were too close to the ground, had too few laser returns, or were in the middle of dense vegetation. On the other hand, lines were also detected in case of line-shaped objects such as short stone walls or deep tracks from vehicles (i.e., the ridges between the wheel pairs). The algorithm also detected longer lines such as ditches and roads. A better detection of longer lines in the point cloud or in the DTM would decrease the number of false positives. Additionally, the performance depends on the site conditions and the study area contained big piles of storm-felled trees in some places that were difficult to separate completely. The results might be better in a less complex test site.

The algorithm depends on geometrical information and a stem is detected only if the height difference between the stem and the surrounding is big enough. A possible improvement would be to select the ALS returns based on radiometric information: amplitude and, in the case of full waveform ALS data, echo width (Mücke et al., 2013).

\section{ACKNOWLEDGEMENTS}

The study was financed by the Swedish Research Council for Environment, Agricultural Sciences and Spatial Planning. The data collection was financed by the Swedish National Space Board. We would like to thank Mattias Nyström at the Swedish University of Agricultural Sciences for valuable discussions about the algorithms.

\section{REFERENCES}

Bailly, J.S., Lagacherie, P., Millier, C., Puech, C. and Kosuth, P., 2008. Agrarian landscapes linear features detection from LiDAR: application to artificial drainage networks. International Journal of Remote Sensing, 29(12): 3489-3508.

Bater, C.W., Coops, N.C., Gergel, S.E., LeMay, V. and Collins, D., 2009. Estimation of standing dead tree class distributions in northwest coastal forests using lidar remote sensing. Canadian Journal of Forest Research-Revue Canadienne De Recherche Forestiere, 39(6): 1080-1091.

Blanchard, S.D., Jakubowski, M.K. and Kelly, M., 2011. Object-based image analysis of downed logs in disturbed forested landscapes using lidar. Remote Sensing, 3(11): 24202439.

Fischler, M.A. and Bolles, R.C., 1981. Random Sample Consensus: A Paradigm for Model Fitting with Applications to Image Analysis and Automated Cartography. Communications of the ACM, 24(6): 381-395.

Gonzalez, R.C. and Woods, R.E., 2008. Digital Image Processing. Pearson Prentice Hall, Upper Saddle River, New Jersey, 976 pp.

Hill, R.A., Hinsley, S.A., Gaveau, D.L.A. and Bellamy, P.E., 2004. Predicting habitat quality for Great Tits (Parus major) with airborne laser scanning data. International Journal of Remote Sensing, 25(22): 4851-4855.

Hinsley, S.A. et al., 2008. Effects of structural and functional habitat gaps on breeding woodland birds: working harder for less. Landscape Ecology, 23(5): 615-626.

Kraus, K. and Pfeifer, N., 1998. Determination of terrain models in wooded areas with airborne laser scanner data. ISPRS Journal of Photogrammetry and Remote Sensing, 53(4): 193203.

Lesak, A.A. et al., 2011. Modeling forest songbird species richness using LiDAR-derived measures of forest structure. Remote Sensing of Environment, 115(11): 2823-2835.

Mücke, W., Deák, B., Schroiff, A., Hollaus, M. and Pfeifer, N., 2013. Detection of fallen trees in forested areas using small footprint airborne laser scanning data. Canadian Journal of Remote Sensing, 39(S1): S1-S9.

Müller, J. and Brandl, R., 2009. Assessing biodiversity by remote sensing in mountainous terrain: the potential of LiDAR to predict forest beetle assemblages. Journal of Applied Ecology, 46(4): 897-905.

Pesonen, A., Maltamo, M., Eerikäinen, K. and Packalén, P., 2008. Airborne laser scanning-based prediction of coarse woody debris volumes in a conservation area. Forest Ecology and Management, 255(8-9): 3288-3296.

Pfeifer, N., Stadler, P. and Briese, C., 2001. Derivation of digital terrain models in the SCOP++ environment. In: K. Torlegård and J. Nelson (Editors), OEEPE Workshop on Airborne Laserscanning and Interferometric SAR for Detailed Digital Terrain Models, Stockholm, Sweden.

Schmidt, S., 2007. Lebensgeschichte Tiefdruckgebiet HANNO, Berlin, Germany http://www.met.fuberlin.de/wetterpate/Lebensgeschichten/Tief_HANNO_12_01_ 07.htm (May 16, 2013).

Shan, J. and Toth, C., 2009. Topographic Laser Ranging and Scanning: Principles and Processing. CRC Press/Taylor \& Francis Group, Boca Raton, FL.

Sithole, G. and Vosselman, G., 2003. ISPRS Comparison of Filters, http://www.itc.nl/isprswgiii-3/filtertest/ (June 6, 2013).

TU Vienna, D.o.G.a.G., Research Group Photogrammetry, 2013. SCOP++, Vienna, Austria http://photo.geo.tuwien.ac.at/software/scop/ (June 6, 2013).

Vierling, K.T., Vierling, L.A., Gould, W.A., Martinuzzi, S. and Clawges, R.M., 2008. Lidar: shedding new light on habitat characterization and modeling. Frontiers in Ecology and the Environment, 6(2): 90-98. 